\title{
Anxiety, depression and hyperventilation symptoms in treatment-resistant severe asthma
}

\author{
Tan Li Leng karen*, Tay Chee Kiang, Yii Anthony, Chan Kwok Wai Adrian, Lapperre Therese Sophie, \\ Koh Mariko Siyue \\ From 2nd International Severe Asthma Forum (ISAF) \\ Athens, Greece. 13-15 November 2014
}

\section{Background}

Psychological morbidity is associated with frequent asthma exacerbations, higher health care utilization, as well as near-fatal and fatal asthma. The prevalence of psychological comorbidities in patients with severe asthma is not well-studied. The aim of our study was to evaluate the prevalence of anxiety, depression and hyperventilation, and correlate these symptoms with asthma control, exacerbation frequency and lung function in severe asthmatics.

\section{Methods}

Patients who fulfilled the WHO definition of "treatmentresistant severe asthma" (at least combination high-dose inhaled corticosteroids and long-acting beta agonists) were included. Patients literate in English completed the Hospital Anxiety and Depression Scale (HADS) and Nijmegen Questionnaire during a regular doctor's visit at our Severe Asthma clinic. The HADS questionnaire comprises 7 anxiety and 7 depression questions. A cut-off score of $\geq 8$ indicates a probable case of anxiety or depression. Nijmegen Questionnaire is a screening instrument for hyperventilation. A score of $\geq 23$ suggests hyperventilation. Relation between these scores and Asthma Control Test, exacerbation frequency, health care utilization and lung function test results were analyzed.

\section{Results}

52 patients were included in the analysis: 24 (46.2\%) male, mean age $37.5 \pm 16.6$ years, mean ACT score $16.8 \pm 4.5$. The prevalence of anxiety was $44.2 \%$, depression was $19.2 \%$ and hyperventilation was $28.8 \%$. Patients with anxiety were more likely to have uncontrolled asthma (defined as Asthma Control Test score of 19 or less) compared to those without $(87.0 \%$ vs. $51.7 \%, \mathrm{p}=0.009)$. Similarly, patients with hyperventilation were more likely to have uncontrolled asthma compared to those without (93.3\% vs. $56.8 \%, \mathrm{p}=0.011$ ). There was no association between depression and asthma control. Patients with anxiety had lower $\mathrm{FEV}_{1} \%$ predicted compared to those without (69.4 $\pm 17.2 \%$ vs. $81.2 \pm 21.2 \%, \mathrm{p}=0.036$ ). There was no association between depression or hyperventilation and $\mathrm{FEV}_{1}$. No association was found between anxiety, depression or hyperventilation and frequency of asthma exacerbations.

\section{Conclusion}

A high prevalence of anxiety, hyperventilation and depression exists amongst our severe asthmatics. Hyperventilation and anxiety were associated with uncontrolled asthma, and presence of anxiety was associated with a lower $\mathrm{FEV}_{1} \%$ predicted. This suggests that there is an objective association between anxiety and uncontrolled asthma, although the causal link remains unclear.

Published: 23 March 2015

doi:10.1186/2045-7022-5-S2-P7

Cite this article as: Li Leng karen et al:: Anxiety, depression and hyperventilation symptoms in treatment-resistant severe asthma. Clinical and Translational Allergy 2015 5(Suppl 2):P7. 